\title{
Jeotermal Akışkanın Hidrokimyasal Karakterizasyonunun Belirlenmesi: Simav (Kütahya) Örneği
}

\author{
Mine Çardak ${ }^{1 *}$, Deniz Şanlıyüksel Yücel ${ }^{2}$, Mustafa Ay ${ }^{3}$, \\ Tuğba Söküt Acar ${ }^{4}$, Özlem Erol Tinaztepe ${ }^{5}$ \\ ${ }^{1}$ Çanakkale Onsekiz Mart Üniversitesi, Çanakkale Uygulamalı Bilimler Yüksekokulu Balıkçılık Teknolojisi \\ Bölümü \\ ${ }^{2}$ Çanakkale Onsekiz Mart Üniversitesi, Mühendislik Fakültesi, Maden Mühendisliği Bölümü \\ ${ }^{3}$ Çanakkale Onsekiz Mart Üniversitesi, Çanakkale Uygulamalı Bilimler Yüksekokulu, Gıda Teknolojisi Bölümü \\ ${ }^{4}$ Çanakkale Onsekiz Mart Üniversitesi, Fen-Edebiyat Fakültesi, İstatistik Bölümü, \\ ${ }^{5}$ Çanakkale Onsekiz Mart Üniversitesi, Sağlık Hizmetleri Meslek Yüksekokulu, Tıbbi Hizmetler ve Teknikler \\ Programı
}

01.04.2019 Geliş/Received, 24.05.2019 Kabul/Accepted

\section{Özet}

Yüksek sıcaklık ve basınç altında jeotermal akışkan ile uzun süre etkileşim içerisinde olan kayaçtaki birçok metal(loid) çözünerek suya geçmektedir. Jeotermal akışkanın içerdiği yüksek metal ve iz element konsantrasyonu nedeni ile çevresindeki su kaynakları üzerinde olumsuz etkileri bulunmaktadır. Kütahya ili Simav ilçesinde Eynal, Naşa ve Çitgöl jeotermal alanları yer almaktadır. Jeotermal akışkan termal turizm, konut ve sera 1sıtması amaçlı olarak kullanılmakta, atık suyu Simav çayına deşarj edilmektedir. Bölgede reenjeksiyon kuyusu bulunmamaktadır. Bu çalışmada Simav ilçesindeki jeotermal akışkanın hidrokimyasal karakterizasyonunun belirlenmesi ve olası çevresel etkilerinin değerlendirilmesi amaçlanmıştır. $\mathrm{Bu}$ amaç ile Eynal, Naşa ve Çitgöl jeotermal alanlarından 2014 ve 2015 yıllarında yağışlı ve kurak dönem olmak üzere $2 \mathrm{kez}$ ve toplam 22 jeotermal sondajdan su örneklemesi yapılmıştır. Elde edilen hidrokimyasal analiz sonuçları ulusal standartlarla karşılaştırılarak, istatistiksel olarak değerlendirilmiştir. Jeotermal akışkanın sıcaklığ 160.05 $88.8{ }^{\circ} \mathrm{C}$, elektriksel iletkenlik değeri $1596-2271 \mu \mathrm{S} / \mathrm{cm}$ arasında ölçülmüştür. Jeotermal akışkanın katyon dizilimi $\mathrm{Na}^{+}>\mathrm{K}^{+}>\mathrm{Ca}^{2+}>\mathrm{Mg}^{2+}$, anyon dizilimi ise $\mathrm{SO}_{4}{ }^{2-}>\mathrm{HCO}_{3}^{-}>\mathrm{Cl}^{-}$ şeklinde olup, akışkanın su tipi Na-SO $\mathrm{S}_{4}-\mathrm{HCO}_{3}{ }^{\prime}$ tır. As $(684 \mu \mathrm{g} / \mathrm{l}), \mathrm{B}(4203 \mu \mathrm{g} / \mathrm{l}), \mathrm{Fe}(612 \mu \mathrm{g} / \mathrm{l})$ ve $\mathrm{Mn}(531 \mu \mathrm{g} / \mathrm{l})$ konsantrasyonu limit değerlerin üzerindedir. Su Kirliliği Kontrolü Yönetmeliği'ne göre jeotermal akışkan $\mathrm{Na}^{+}, \mathrm{SO}_{4}{ }^{2-}$, As ve $\mathrm{B}$ konsantrasyonuna göre çok kirlenmiş sular sınıfında yer almaktadır.

Anahtar Kelimeler: çevresel etki, jeotermal akışkan, hidrokimya, Simav 


\title{
Hydrochemical Characterization of Geothermal Fluid: A case study from Simav (Kütahya)
}

\begin{abstract}
Many metal(loid)s in rocks are dissolved during long-term interactions with geothermal fluids at high temperature and pressure. Due to the high metal and trace element concentration contained in geothermal fluids, they have negative effects on surrounding water resources. The Eynal, Naşa and Çitgöl geothermal fields are located in Simav county in Kütahya province. The geothermal fluids are used for thermal tourism, residential and greenhouse heating, with wastewater discharged into the Simav river. There is no reinjection well in the region. This study aimed to determine the hydrochemical characterization and to assess the probable environmental effects of the geothermal fluid in Simav county. With this aim, water samples were taken from the Eynal, Naşa and Çitgöl geothermal fields twice during rainy and dry periods in 2014 and 2015 and from a total of 22 geothermal well. The hydrochemical analysis results were compared with national standards and statistically assessed. The geothermal fluids had temperature of $60.05-88.8{ }^{\circ} \mathrm{C}$ with electrical conductivity values measured as $1596-2271 \mu \mathrm{S} / \mathrm{cm}$. The cation sequence in the geothermal fluid was $\mathrm{Na}^{+}>\mathrm{K}^{+}>$ $\mathrm{Ca}^{2+}>\mathrm{Mg}^{2+}$, with anion sequence of $\mathrm{SO}_{4}{ }^{2-}>\mathrm{HCO}_{3}{ }^{-}>\mathrm{Cl}^{-}$and the water type of the fluid was $\mathrm{Na}-\mathrm{SO}_{4}-\mathrm{HCO}_{3}$. Arsenic $(684 \mu \mathrm{g} / \mathrm{l}), \mathrm{B}(4203 \mu \mathrm{g} / \mathrm{l}), \mathrm{Fe}(612 \mu \mathrm{g} / \mathrm{l})$, and $\mathrm{Mn}(531 \mu \mathrm{g} / \mathrm{l})$ concentrations were above limit values. According to the Turkish Water Pollution Control Regulations, the geothermal fluids are classified as heavily polluted water according to $\mathrm{Na}^{+}$, $\mathrm{SO}_{4}{ }^{2-}$, As and $\mathrm{B}$ concentrations.
\end{abstract}

Keywords: environmental effect, geothermal fluid, hydrochemistry, Simav

\section{Giriş}

Jeotermal enerji, yer kabuğunun çeşitli derinliklerinde birikmiş 1sının oluşturduğu, sıcaklıkları sürekli olarak bölgesel atmosferik ortalama sıcaklığın üzerinde olan ve çevresindeki normal yer altı ve yerüstü sularına göre daha fazla erimiş mineral, çeşitli tuzlar ve gazlar içerebilen sıcak su ve buharın yeryüzüne taşıdığı ısı enerjisi olarak tanımlanır (Akkuş, 2002). Genç tektonizma ve volkanizmanın yoğun olduğu, Alp-Himalaya orojenik kuşağı içerisinde yer alan Türkiye, jeotermal kaynak zenginliği açısından dünyada yedinci sırada bulunmakta olup, Avrupa'da ise birinci sırada yer almaktadır (Şanlıyüksel ve Baba, 2011). Türkiye'deki ilk jeotermal çalışmalar 1960'lı yıllarda Maden Tetkik ve Arama Genel Müdürlüğü tarafindan başlatılmıştır. Türkiye'de sıcaklığı $20-287^{\circ} \mathrm{C}$ arasında değişen yaklaşık 2000 sıcak ve mineralli su kaynağ1 ve ekonomik ölçekte kullanılabilen 227 jeotermal alan belirlenmiştir (Şimşek, 2015). Türkiye'nin teorik jeotermal enerji potansiyeli 31.500 ile $60.000 \mathrm{MWt}$ arasinda tahmin edilmekte olup fiili kullanılabilir teknik kapasitesi ise $4809 \mathrm{MWt}$ olarak hesaplanmaktadır (Zaim ve Çavşi, 2018).

Metaller sucul ekosistemlere doğal kaynakların yanı sıra artan antropojenik etki (kentsel ve endüstriyel etkiler, madencilik faaliyetlerinin etkileri, jeotermal kaynaklı etkiler vb.) ile ulaşmaktadır. Ağır metaller ve arsenik doğrudan kansere neden olan kimyasallar olarak tüm Dünya'da dikkatle takip edilmektedir. Bangladeş, Hindistan, Amerika Birleşik Devletleri, Arjantin, Şili, Tayvan ve Çin gibi pek çok ülkede su kaynaklarındaki yüksek metal konsantrasyonlarına bağlı olarak sağlık problemleri saptanmıştır (Baba ve Sozbilir, 2012). Yüksek sıcaklık ve basınç altında su-kayaç etkileşimi çok sayıda mineral, metal ve iz 
elementlerin doğal çözünmesinden sorumludur. Jeotermal akışkanın içerdiği yüksek konsantrasyondaki metal ve iz elementlerin yüzey ve yeraltı sularına karışımı ile önemli çevresel kirliliğe neden olmaktadır (Baba ve Armannsson, 2006). Ayrıca yapılan deşarj sonrasında alıcı ortam sıcaklığında oluşan ani değişimler sucul yaşam üzerinde tahribat yaratmaktadır (Gündüz ve ark., 2012). Davraz ve ark. (2017) Büyük Menderes Havzası'nda yer alan Hüdai jeotermal alanındaki jeotermal akışkanın yüzey sularına karıştığını ve yüzey sularında $\mathrm{As}, \mathrm{Al}, \mathrm{B}, \mathrm{Fe}, \mathrm{Cr}, \mathrm{Li}, \mathrm{Pb}, \mathrm{Mn}$ ve $\mathrm{Zn}$ konsatrasyonunun artışına sebep olduğunu saptamıştır. Özen Balaban ve ark. (2017) Salihli jeotermal akışkanının As, B, Br, Fe ve Ni element içeriğinin içme ve sulama suyu standartlarından daha yüksek olduğunu tespit etmiştir. Jeotermal akışkanın kimyasal içeriği rezervuar kayaçlarına bağlı olarak bölgeden bölgeye farklılık göstermektedir. Türkiye'de potansiyel oluşturan jeotermal alanların \% 78'i Batı Anadolu'da yer almaktadır. Batı Anadolu'daki jeotermal kaynaklar genellikle Batı Anadolu plakasının jeolojik özelliği olan arsenik, bor, antimon, demir ve mangan ile ilişkilendirilmektedir (Gündüz ve ark., 2012; Baysal ve Gündüz, 2016).

Batı Anadolu'daki en önemli jeotermal alanlardan olan Eynal, Naşa ve Çitgöl, Kütahya ili Simav ilçesi sınırlarında yer almaktadır (Şekil 1.1). Simav ilçesi $1515 \mathrm{~km}^{2}$ yüz ölçüme sahip olup, bağlı olduğu Kütahya il merkezine $142 \mathrm{~km}$ uzaklıktadır. İlçenin toplam nüfusu 64015 kişidir (TUIK, 2018). Simav ilçesi ve çevresi, Ege Bölgesi iklim tipi ile İç Anadolu iklim tipi arasında geçiş bölgesi özelliklerini gösteren Orta Ege iklim bölgesinde yer almaktadır (Şimşek ve Gündüz, 2007). Kütahya meteoroloji istasyonu 1929-2017 yılları arasındaki ölçüm verilerine göre yıllık ortalama sıcaklık değeri $10.7^{\circ} \mathrm{C}^{\prime}$ dir. En düşük sıcaklık 29.12.1948 tarihinde $-28.5{ }^{\circ} \mathrm{C}$, en yüksek sıcaklık 29.07.2000 tarihinde $39.5{ }^{\circ} \mathrm{C}$ ölçülmüştür. Sıcaklık ortalamasının en düşük olduğu ay $0.3{ }^{\circ} \mathrm{C}$ ile Ocak ayı, en yüksek olduğu ay $20.8{ }^{\circ} \mathrm{C}$ ile Temmuz ayıdır. Ortalama aylık toplam yağış miktarı $558 \mathrm{~mm}$, yağışıı en düşük olduğu ay $15.8 \mathrm{~mm}$ ile Ağustos ayıdır. En yüksek kar yağışı 26.01 .2006 tarihinde $60 \mathrm{~cm}$ ölçülmüştür. Simav ilçesinde yer alan basınçlı akifer niteliğinde olan ve jeotermal sahaların oluşmasına neden olan derin akifer sistemi olup, bölgede jeotermal akışkanın üretilmesi amacıyla derinliği 1000 m'ye ulaşan sondajlar açılmıştır (Gündüz ve ark., 2012). Sondajlardan elde edilen verilere göre bölgedeki jeotermal akışkanın sıcaklığg 42 ile $162{ }^{\circ} \mathrm{C}$, debisi ise 0.2 ile 80 1/sn arasında değişmektedir. Eynal, Naşa ve Çitgöl jeotermal alanlarındaki akışkan termal turizm, konut ve sera 1sıtması amaçlı olarak kullanılmakta, atık suyu kontrolsüz olarak çevredeki derelere deşarj edilmektedir. Bölgede reenjeksiyon kuyusu bulunmamaktadır. $\mathrm{Bu}$ çalışmada jeotermal akışkanın hidrokimyasal özelliklerinin belirlenerek olası çevresel etkilerinin değerlendirilmesi amaçlanmıştır. 


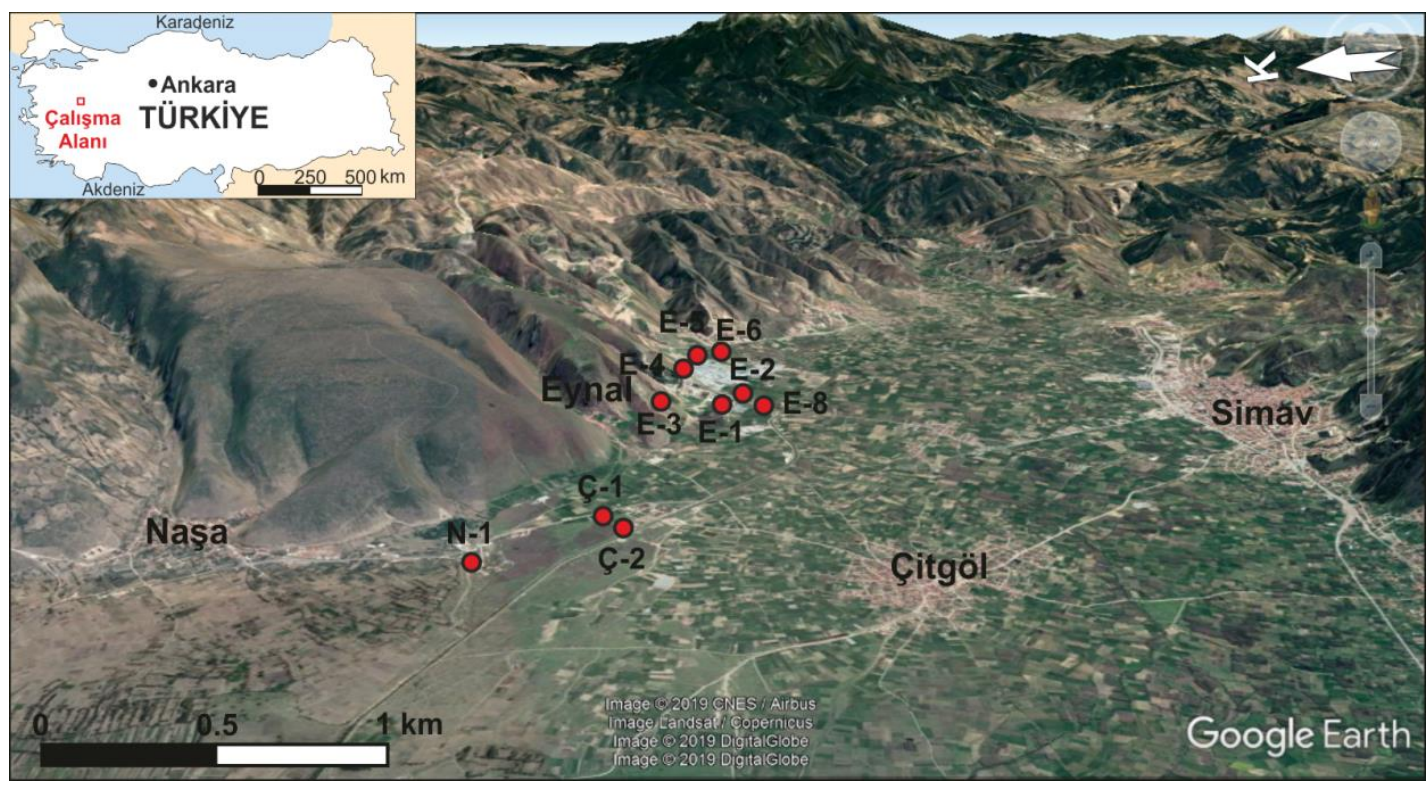

Şekil 1.1. Çalışma alanının ve jeotermal sondajların 2018 yılı uydu görüntüsündeki konumu

\section{Materyal ve Yöntem}

\subsection{Arazi Çalışmaları}

Simav ilçesindeki arazi çalışmaları kurak ve yağışlı dönemlerde (Eylül 2014 ve Mart 2015) gerçekleştirilmiştir. Eynal jeotermal alanındaki sondajlardan sekiz (E-1'den E-8'e kadar), Çitgöl jeotermal alanındaki sondajlardan iki (Ç-1 ve Ç-2), Naşa jeotermal alanındaki sondajlardan ise bir (N-1) örnekleme yapılmıştır. Arazi çalışmaları sırasında jeotermal sondajların koordinatları ve yükseklik değerleri Garmin Nuvi 200 marka el tipi GPS ile belirlenmiştir. Jeotermal akışkanın sıcaklık $\left(\mathrm{T},{ }^{\circ} \mathrm{C}\right), \mathrm{pH}$, elektriksel iletkenlik $(\mathrm{EC}, \mu \mathrm{S} / \mathrm{cm})$, değerleri arazide WTW Multi 340i pH/iletkenlik ölçüm cihazı ile ölçülmüştür. Kullanılan proplar her ölçüm öncesi ve ölçüm sonrasında saf su ile yıkanarak temizlenmiş, her arazi çalışmasından önce buffer solüsyonları ile günlük kalibrasyonları yapıldıktan sonra kullanılmıştır. Örnekleme için ilk kez kullanılacak olan sert plastik su kapları kullanılmıştır. Suların örneklemesi sırasında, örnek kapları doldurulmadan önce örnekleme yapılacak sularla üç kez çalkalanmıştır. İndüktif eşleşmiş plazma-kütle spektrometresi (ICP-MS) analizi için alınan su örnekleri, $0.45 \mu \mathrm{m}$ gözenekli filtrelerle (Millipore), $50 \mathrm{ml}$ 'lik kaplara filtrelenmiştir. Elementlerin dibe çökmelerini ve yüzeye tutunmalarını önlemek amacıyla, su örneklerinin pH'ını 2-3 aralığına indirmek için $0.2 \mathrm{ml}$ yüksek saflıktaki nitrik asit (Merck) ilave edilmiştir. Filtreleme işlemi, iyon kromotografisi (IC) analizleri için alınan örneklerde de tekrarlanmıştır ancak, nitrik asit ilavesi yapılmamıştır. Tüm örnekler su kabında hava kalmayacak şekilde doldurularak arazi tipi buzdolabında saklanıp $\left(+4{ }^{\circ} \mathrm{C}\right)$, laboratuvara ulaştırılmıştır.

\subsection{Laboratuvar Çalışmaları}

Jeotermal akışkanın sodyum $\left(\mathrm{Na}^{+}\right)$, potasyum $\left(\mathrm{K}^{+}\right)$, kalsiyum $\left(\mathrm{Ca}^{2+}\right)$, magnezyum $\left(\mathrm{Mg}^{2+}\right)$, alüminyum ( $\mathrm{Al})$, arsenik $(\mathrm{As})$, bakır $(\mathrm{Cu})$, baryum $(\mathrm{Ba})$, bor $(\mathrm{B})$, çinko $(\mathrm{Zn})$, demir $(\mathrm{Fe})$, kobalt $(\mathrm{Co})$, krom $(\mathrm{Cr})$, kurşun $(\mathrm{Pb})$, lityum $(\mathrm{Li})$, mangan $(\mathrm{Mn})$, silisyum $(\mathrm{Si})$ analizleri ICPMS (Nexion 2000, Perkin Elmer, Kağıthane, İstanbul) cihazı ile ACME Laboratuvarında Kanada'da yaptırılmıştır. Analizi yapılan elementlerin dedeksiyon limitleri $\mu \mathrm{g} / \mathrm{l}$ olarak; $\mathrm{Na}$ (50), K (50), Ca (50), Mg (50), Al (1), As (0.5), B (5), Ba (0.05), Co (0.02), Cr (0.5), Cu (0.1), 
Fe (10), Li (0.1), Mn (0.05) Ni (0.2), Pb (0.1), Si (40), Zn (0.5) şeklindedir. Klorür $\left(\mathrm{Cl}^{-}\right)$ve sülfat $\left(\mathrm{SO}_{4}{ }^{2-}\right)$ analizleri IC (LC-20A SP, Shimadzu,Japan) cihazı ile Çanakkale Onsekiz Mart Üniversitesi Bilim ve Teknoloji Uygulama ve Araştırma Merkezi yaptırılmıştır. Bikarbonat $\left(\mathrm{HCO}_{3}{ }^{-}\right)$tayini Çanakkale Onsekiz Mart Üniversitesi Maden Mühendisliği Bölümü Maden İşletme laboratuvarında titrasyon yöntemi kullanılarak yapılmıştır.

\section{3. İstatistiksel Analizler}

Araştırma için gerekli olan hidrokimyasal veriler elde edildikten sonra bilgisayar ortamına SPSS (SPSS 19.0, IBM, Armonk, NY, ABD) paket programı ile aktarılmıştır. Her bir değişkene ait betimsel istatistikler elde edilmiştir (ortalama \pm standart sapma). Parametrik testlerin uygulanabilmesi için gerekli olan koşullardan biri değişkenlerin normal ya da normale yakın bir dağılım göstermesidir. Bu doğrultuda verilerin normal dağılan bir kitleden gelip gelmediğini sınamak için Shapiro-Wilk testi uygulanmıştır. Test sonucunda dokuz değişkenin (sıcaklık, $\mathrm{pH}, \mathrm{Ca}^{2+}, \mathrm{Ba}, \mathrm{Cu}, \mathrm{Fe}, \mathrm{Mn}, \mathrm{Ni}, \mathrm{Pb}$ ) normal dağılıma uygunluk göstermediği saptanmıştır. Örneklem genişliği $(n=11)$ yeterince büyük olmadığından ve değişkenlerin yaklaşık \% 40'1 normal dağılım sergilemediğinden istatistiksel testlerde parametrik olmayan yöntemler kullanılmıştır. İki değişken arasındaki ilişki belirlenirken parametrik olmayan korelasyon katsayısı olan Sperman's rho katsayısı kullanılmıştır. Araştırmada önem düzeyleri 0.01 ve 0.05 olarak alınmıştır.

\section{Bulgular ve Tartışma}

Simav GD-KB yönlü bir graben ovası olup, sahada beş ana jeolojik birim gözlenmektedir. Bu birimler yaşlıdan gence doğru Paleozoyik yaşlı Simav metamorfitleri, Paleosen yaşlı Eğrigöz graniti, Orta-Üst Miyosen yaşlı Kızılbük formasyonu, Alt Kuvaterner yaşlı Naşa bazaltı ve Kuvaterner yaşlı alüvyondur (Gündüz ve ark., 2010; 2012) (Şekil 3.1). Çalışma alanı ve yakın çevresinde depremsellik açısından oldukça yoğun bir aktivite söz konusudur. Bölgede aletsel dönemde meydana gelmiş en büyük deprem 28 Mart 1970 tarihinde meydana gelmiş olan M=7.2 büyüklüğündeki Gediz depremidir (Ateş ve Tutkun, 2014). Çalışma sahasındaki Eynal, Çitgöl ve Naşa jeotermal alanlar fay hatları boyunca dizilmiş olup, tektonizmaya bağlı olarak gelişen bu jeotermal kaynakların rezervuar kayacı, bölgede yüksek veren Simav metamorfitleri içerisinde yer alan mermerler ve alanda yaygın olarak gözlenen Neojen yaşlı kumtaş1, kiltaşı, marn ve volkanik kayaçlardan oluşan birimlerdir. Bölgedeki temel birimleri kesen Eğrigöz graniti ile Naşa bazaltı sıcak su kaynaklarının 1sıtıcı kayacını oluşturmaktadır. Alüvyon ise örtü kaya özelliğindedir (Gündüz ve ark., 2012). Eynal sahasında 1990 yılında Maden Tetkik ve Arama Genel Müdürlüğü tarafından jeotermal akışkanın elde edildiği akifere fay hatları boyunca açılan ve derinliği $958 \mathrm{~m}$ olan sondajda $162{ }^{\circ} \mathrm{C}$ kuyu dibi sıcaklığ ve 72 1/s debi saptanmıştır (MTA, 2001; Gemici ve Tarcan, 2002). Simav ilçesinde $167{ }^{\circ} \mathrm{C}$ rezervuar sicaklığ ile 8830 konut 1sitılmakta ve Simav Eynal'da $265.000 \mathrm{~m}^{2}$ lik alanda sera 1sitılması yapılmaktadır (Mertoğlu ve ark., 2015; Akkuş ve Alan, 2016).

Çalışma alanındaki jeotermal akışkanının sıcaklık değerleri $60.05-88.8^{\circ} \mathrm{C}$ arasında değişmektedir (Çizelge 3.1). En yüksek sıcaklık Eynal jeotermal alanındaki E-8 no'lu sondajda ölçülmüştür. Sudaki çözünmüş toplam iyon miktarı ile EC değerleri arasında genellikle doğrusal bir ilişki vardır (Şahinci, 1991; Şanlıyüksel Yücel ve Yücel, 2017). Jeotermal akışkanın EC değeri 1596-2271 $\mu \mathrm{S} / \mathrm{cm}$ arasındadır. Bu değer TS 266 (2005) tarafından tavsiye edilen maksimum değer olan $400 \mu \mathrm{S} / \mathrm{cm}$ 'in oldukça üzerindedir. Jeotermal akışkanın pH'ı bazik karakterde olup, 7.29-8.4 arasında ölçülmüştür. Temel anyon ve katyonlar incelendiğinde jeotermal akışkanın $\mathrm{Na}^{+}, \mathrm{Li}^{+}, \mathrm{SO}_{4}{ }^{2-}$ ve $\mathrm{HCO}_{3}{ }^{-}$açısından zengin olduğu görülmüştür. Jeotermal akışkanın katyon dizilimi $\mathrm{Na}^{+}>\mathrm{K}^{+}>\mathrm{Ca}^{2+}>\mathrm{Mg}^{2+}$, anyon dizilimi ise $\mathrm{SO}_{4}{ }^{2-}>\mathrm{HCO}_{3}>\mathrm{Cl}^{-}$şeklinde olup, 
Uluslararası Hidrojeologlar Birliği su sınıflamasına göre tüm jeotermal akışkanların su tipi $\mathrm{Na}-\mathrm{SO}_{4}-\mathrm{HCO}_{3}$ 'tır (Şekil 3.2). Simav'daki jeotermal sondajlarda $\mathrm{Na}^{+}$konsantrasyonu 278.15$506.5 \mathrm{mg} / 1$ arasında olup, ortalama değer $378.4 \mathrm{mg} / \mathrm{l}^{\prime}$ dir. $\mathrm{SO}_{4}{ }^{2-}$ iyonu için minimum, maksimum ve ortalama değerler sırası ile $341.26,575.2 \mathrm{ve} 475.21 \mathrm{mg} / \mathrm{l}$ 'dir. En düşük $\mathrm{Na}$ ve $\mathrm{SO}_{4}{ }^{2-}$ konsantrasyonu Naşa, en yüksek değer Eynal jeotermal alanında ölçülmüştür. Su Kirliliği Kontrolü Yönetmeliği'ne göre jeotermal akışkan $\mathrm{Na}^{+}$ve $\mathrm{SO}_{4}{ }^{2-}$ için çok kirlenmiş sular (sınıf IV) sınıfında yer almaktadır. Sodyum potasyum oranı, sıcaklığa bağlı mineral sıvı dengeleri tarafından kontrol edilir. Örnekleme yapılan jeotermal akışkanın $\mathrm{Na} / \mathrm{K}$ oranı 5.82 ile 8.68 arasındadır. Düşük Na/K oranı $(<15)$, daha az soğuk su ile karışarak, yüzeye hızla ulaşan yüksek sicaklıklı jeotermal sularda ortaya çıkma eğilimindedir (Nicholson, 1993; Gemici ve Tarcan, 2002). Jeotermal sahalarda kayaçların doğası ve suyun kökenini belirlemek için, yaygın olarak en az tepkimeye girme eğilimine sahip iyon olan $\mathrm{Cl}^{-}$kullanılır (Palabıyık, 2006). Bir kez çözüldükten sonra başka minerallerin bünyesine kolay girmemesi nedeniyle doğrudan jeotermal akışkanı karakterize eder (Nicholson, 1993). Yüksek $\mathrm{Cl}^{-}$derişimi doğrudan, derinden ve yüksek debili bir beslenmeyi, düşük $\mathrm{Cl}^{-}$derişimi ise yüzey sularının giriş doğrultularını belirtir (Eroğlu ve Aksoy, 2003). Jeotermal akışkanın $\mathrm{Cl}^{-}$konsantrasyonu 45.84-105.6 mg/l arasında ölçülmüş olup, Su Kirliliği Kontrolü Yönetmeliği'ne göre jeotermal akışkan az kirlenmiş sular (sınıf II) sınıfında yer almaktadır. Trityum izotopu içeriğinde göre Eynal, Çitgöl ve Naşa jeotermal akışkanları sırasıyla $0.36 \pm 0.27 \mathrm{TU}, 0.64 \pm 0.28 \mathrm{TU}$ ve $1.44 \pm 0.28 \mathrm{TU}$ değerlerine sahiptir (Bayram ve Şimşek, 2005). Naşa'daki jeotermal akışkan diğer jeotermal sahalara nazaran daha yüksek trityum ve daha düşük $\mathrm{EC}$ ve $\mathrm{Cl}^{-}$içeriğine sahip olduğundan diğer jeotermal akışkanlara göre daha genç sular olduğu düşünülmektedir. 


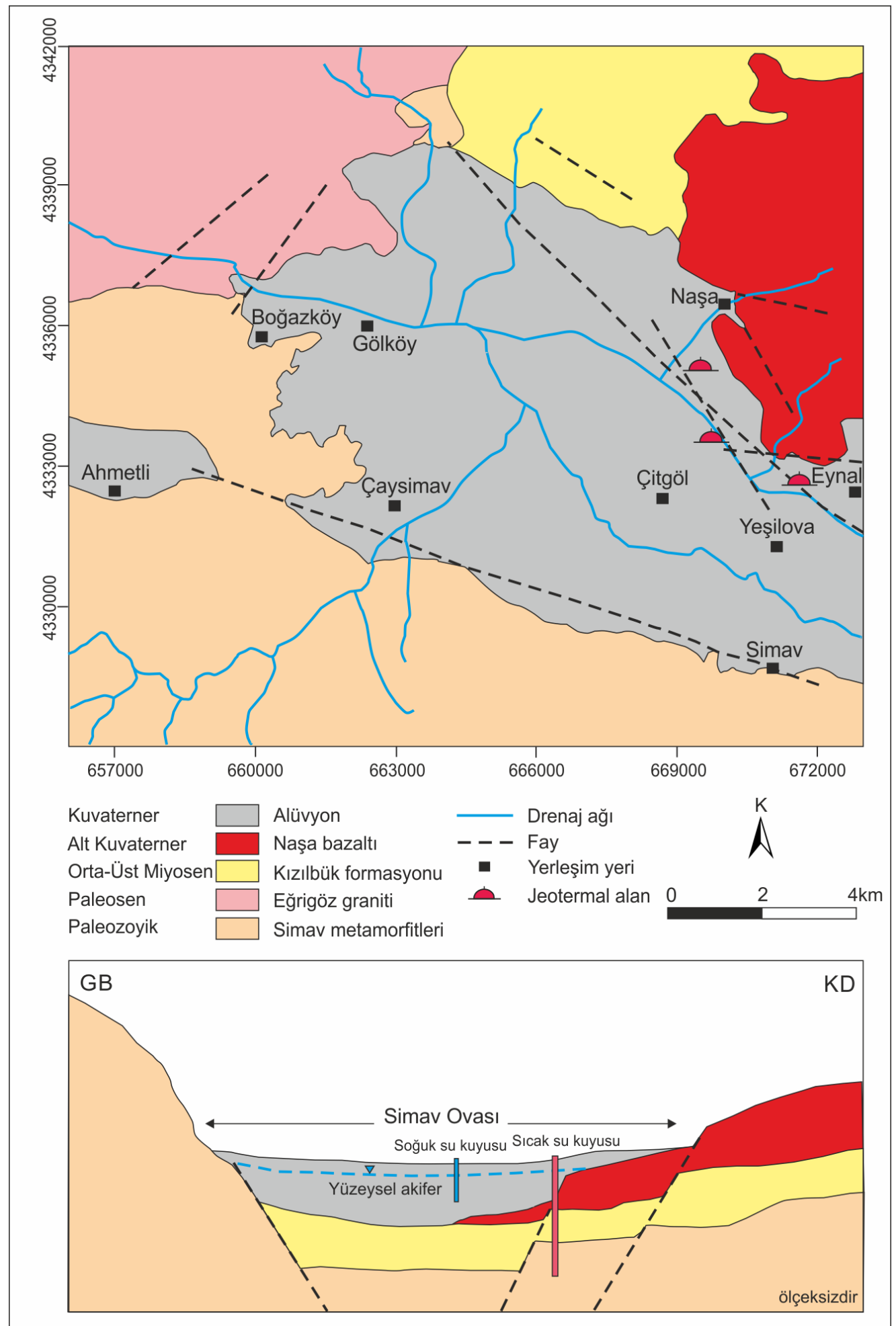

Şekil 3.1. Çalışma alanı ve yakın çevresinin jeoloji haritası ve jeolojik kesiti (Gündüz ve ark., 2010) 
Çizelge 3.1. Simav ovasındaki jeotermal akışkanın hidrokimyasal karakterizasyonu ve Su Kirliliği Kontrolü Yönetmeliği'ne (2008) göre su kalite sinifları

\begin{tabular}{|c|c|c|c|c|c|c|c|c|c|c|c|c|c|c|c|c|}
\hline \multirow{2}{*}{ Parametre } & \multirow{2}{*}{ Birim } & \multicolumn{8}{|c|}{ Eynal jeotermal alanı } & \multicolumn{2}{|c|}{ Çitgöl jeotermal alanı } & \multirow{2}{*}{$\begin{array}{c}\text { Naşa jeotermal alanı } \\
\mathrm{N}-1 \\
\end{array}$} & \multicolumn{4}{|c|}{ Su Kalite Sinıfları } \\
\hline & & E-1 & E-2 & E-3 & E-4 & E-5 & E-6 & E-7 & E-8 & Ç-1 & Ç-2 & & I & II & III & IV \\
\hline $\mathrm{T}$ & ${ }^{\circ} \mathrm{C}$ & 86.2 & 83.7 & 85.7 & 85.6 & 85.4 & 87.6 & 87.8 & 88.8 & 73.55 & 67.4 & 60.05 & 25 & 25 & 30 & $>30$ \\
\hline $\mathrm{pH}$ & - & 7.38 & 7.31 & 7.42 & 7.32 & 7.68 & 7.7 & 7.29 & 7.52 & 8.4 & 7.71 & 7.57 & $6.5-8.5$ & $6.5-8.5$ & $6-9$ & $<6$ veya $>9$ \\
\hline $\mathrm{EC}$ & $\mu \mathrm{S} / \mathrm{cm}$ & 2271 & 2227 & 1666 & 2167 & 2214 & 2006 & 2056 & 1954 & 1681 & 1804 & 1596 & - & - & - & - \\
\hline $\mathrm{Na}^{+}$ & \multirow{7}{*}{$\mathrm{mg} / \mathrm{l}$} & 506.5 & 321.23 & 431.78 & 281.09 & 447.68 & 310.35 & 401.11 & 453.75 & 425.18 & 305.65 & 278.15 & 125 & 125 & 250 & $>250$ \\
\hline $\mathrm{K}^{+}$ & & 64.97 & 47.83 & 57.33 & 48.26 & 58.93 & 49.23 & 50.14 & 63.25 & 48.96 & 45.21 & 33.92 & - & - & - & - \\
\hline $\mathrm{Ca}^{2+}$ & & 32.37 & 41.12 & 45.5 & 36.92 & 28.9 & 37.85 & 35.76 & 29.13 & 37.09 & 42.6 & 63.78 & - & - & - & - \\
\hline $\mathrm{Mg}^{2+}$ & & 1.92 & 4.07 & 8.65 & 2.72 & 7.53 & 2.08 & 7.75 & 1.16 & 1.14 & 2.98 & 10.29 & - & - & - & - \\
\hline $\mathrm{Cl}^{-}$ & & 74.98 & 82.83 & 90.05 & 85.69 & 80.2 & 105.6 & 94.36 & 85.73 & 62.55 & 58.91 & 45.84 & 25 & 200 & 400 & $>400$ \\
\hline $\mathrm{HCO}_{3}^{-}$ & & 550.23 & 326.2 & 484.63 & 255.61 & 496.7 & 261.89 & 407.15 & 420.3 & 499.61 & 332.85 & 428.11 & - & - & - & - \\
\hline $\mathrm{SO}_{4}{ }^{2-}$ & & 575.2 & 468.17 & 507.46 & 489.11 & 528.75 & 430.36 & 472.62 & 551.48 & 467.7 & 395.22 & 341.26 & 200 & 200 & 400 & $>400$ \\
\hline $\mathrm{Al}$ & \multirow{13}{*}{$\mu \mathrm{g} / 1$} & 157 & 186 & 114 & 125 & 208 & 192 & 133 & 146 & 4 & 16 & 9 & 300 & 300 & 1000 & $>1000$ \\
\hline As & & 378.3 & 400.1 & 392 & 684.1 & 678.4 & 594.1 & 325.4 & 327.3 & 432.9 & 317.8 & 204.1 & 20 & 50 & 100 & $>100$ \\
\hline $\mathrm{B}$ & & 3476 & 3798 & 3531 & 3891 & 3706 & 3047 & 4067 & 4203 & 3116 & 2573 & 2448 & 1000 & 1000 & 1000 & $>1000$ \\
\hline $\mathrm{Ba}$ & & 66.78 & 69.18 & 73.03 & 78.29 & 75.22 & 38.79 & 53.05 & 60.64 & 60.64 & 78.45 & 135.62 & 1000 & 2000 & 2000 & $>2000$ \\
\hline $\mathrm{Cr}$ & & 2 & 2.9 & 1.1 & 0.8 & 0.5 & 1.2 & 2.9 & 3.3 & 3 & 1.8 & 1.5 & 20 & 50 & 200 & $>200$ \\
\hline $\mathrm{Cu}$ & & 1.7 & 1.4 & 3.1 & 3 & 2.3 & 5.3 & 2.8 & 1.9 & 1.5 & 1.8 & 2.7 & 20 & 50 & 200 & $>200$ \\
\hline $\mathrm{Fe}$ & & 134 & 36 & 28 & 30 & 54 & 19 & 31 & 17 & 77 & 612 & 44 & 300 & 1000 & 5000 & $>5000$ \\
\hline $\mathrm{Li}$ & & 1575 & 1557 & 922.2 & 1068.4 & 923.2 & 1233 & 1760 & 1566.1 & 1286 & 1071.1 & 419 & - & - & - & - \\
\hline $\mathrm{Mn}$ & & 50.86 & 45.63 & 301.57 & 96.75 & 409.46 & 27.71 & 15.25 & 23.99 & 24.75 & 165.66 & 531.55 & 100 & 500 & 3000 & $>3000$ \\
\hline $\mathrm{Ni}$ & & 1.6 & 1.4 & 1 & 0.8 & 0.3 & 0.6 & 0.8 & 0.5 & 0.3 & 4.2 & 3.6 & 20 & 50 & 200 & $>200$ \\
\hline $\mathrm{Pb}$ & & 0.4 & 1.4 & 0.3 & 1 & 0.7 & 5.7 & 0.9 & 0.2 & 1 & 0.9 & 3.3 & 10 & 20 & 50 & $>50$ \\
\hline $\mathrm{Si}$ & & 93437 & 11535 & 71938 & 65168 & 70966 & 104406 & 130967 & 114702 & 42676 & 95855 & 80295 & - & - & - & - \\
\hline $\mathrm{Zn}$ & & 15.8 & 19.4 & 29.4 & 24 & 4.5 & 12.6 & 5.5 & 3.1 & 4.2 & 24.6 & 11.5 & 200 & 500 & 2000 & $>2000$ \\
\hline
\end{tabular}

Kurak ve yağışlı örnekleme döneminde elde edilen sonuçların ortalama değerleri alınarak çizelge oluşturulmuştur. 
Çizelge 3.2. Jeotermal akışkanın hidrokimyasal parametrelerinin korelasyonu

\begin{tabular}{|c|c|c|c|c|c|c|c|c|c|c|c|c|c|c|c|c|c|c|c|c|c|c|c|c|}
\hline & & $T$ & $\mathrm{pH}$ & EC & $\mathrm{Na}^{+}$ & $\mathrm{K}$ & $\mathrm{Ca}^{2+}$ & $\mathrm{Mg}^{2+}$ & $\mathrm{Cl}^{-}$ & $\mathrm{HCO}_{3}{ }^{-}$ & $\mathrm{SO}_{4}{ }^{2-}$ & $\mathrm{Al}$ & As & $B$ & $\mathrm{Ba}$ & $\mathrm{Cr}$ & $\mathrm{Cu}$ & $\mathrm{Fe}$ & $\mathrm{Li}$ & $\mathrm{Mn}$ & $\mathrm{Ni}$ & $\mathrm{Pb}$ & $\mathrm{Si}$ & $\mathrm{Zn}$ \\
\hline$T$ & $\mathrm{r}$ & ,000 & & & & & & & & & & & & & & & & & & & & & & \\
\hline $\mathrm{pH}$ & $\mathrm{r}$ & ,418 &, 000 & & & & & & & & & & & & & & & & & & & & & \\
\hline $\mathrm{EC}$ & $\mathrm{r}$ & 327 & ,500 & ,000 & & & & & & & & & & & & & & & & & & & & \\
\hline $\mathrm{Na}^{+}$ & $\mathrm{r}$ & 536 &, 073 & 345 & ,000 & & & & & & & & & & & & & & & & & & & \\
\hline $\mathrm{K}^{+}$ & $\mathrm{r}$ & $755^{* *}$ &, 173 & 391 & $918^{* *}$ & ,000 & & & & & & & & & & & & & & & & & & \\
\hline $\mathrm{Ca}^{2+}$ & $\mathrm{r}$ &, 573 & 155 & ,627 &, $655^{*}$ &, $736^{* * *}$ & ,000 & & & & & & & & & & & & & & & & & \\
\hline $\mathrm{Mg}^{2+}$ & $\mathrm{r}$ &, 273 & ,327 & ,236 & ,364 & ,318, & 464 & ,000, & & & & & & & & & & & & & & & & \\
\hline $\mathrm{Cl}^{-}$ & $\mathrm{r}$ & $827^{* * *}$ & , 409 & 191 & 191 & 427 & ,236 & ,009, & ,000 & & & & & & & & & & & & & & & \\
\hline $\mathrm{HCO}_{3}{ }^{-}$ & $\mathrm{r}$ & ,091 & 245 & ,091, & $673^{*}$ & 500 & ,236 & ,082 & ,409 & ,000 & & & & & & & & & & & & & & \\
\hline $\mathrm{SO}_{4}{ }^{2-}$ & $\mathrm{r}$ & $627^{*}$ & ,409 & 536 & $836^{* *}$ & $891^{* * *}$ &, $736^{* *}$ & ,255 & 309 & 391 & ,000 & & & & & & & & & & & & & \\
\hline $\mathrm{Al}$ & $\mathrm{r}$ & 500 & ,273 & $755^{* *}$ & 382 & 500 &, 555 & ,064 & 482 & 155 & 464 &, 000 & & & & & & & & & & & & \\
\hline As & $\mathrm{r}$ & 127 & 036 & 427 & 100 & 200 & ,364 & , 318 & 336 & ,173, & 282 & 436 & ,000 & & & & & & & & & & & \\
\hline$B$ & $\mathrm{r}$ & $655^{*}$ & ,664* & 455 & 409 & 482 &, $627^{*}$ & ,118, & 564 & , 182 & $664^{*}$ & 373 & 255 & ,000 & & & & & & & & & & \\
\hline $\mathrm{Ba}$ & $\mathrm{r}$ &, $729^{*}$ & 087 & ,219 & ,442 & ,506 & 401 & 487 & , $670^{*}$ & ,009 & ,228 &, 355 & , 182 & ,342 & ,000 & & & & & & & & & \\
\hline $\mathrm{Cr}$ & $\mathrm{r}$ & 191 & ,059 & , 050 & 278 & 073 &, 118 & ,474 & ,064 & 155 & 005 & ,223 & ,446 & 228 & ,489 &, 000 & & & & & & & & \\
\hline$\overline{\mathrm{Cu}}$ & $\mathrm{r}$ & 373 &, 082 & ,282 & ,282 & 064 & 145 & 382 & $609^{*}$ & ,364 & ,064 & 082 & 173 & 009 & ,068 & ,606" & ,000 & & & & & & & \\
\hline $\mathrm{Fe}$ & $\mathrm{r}$ &, $655^{*}$ & 309 & 127 & ,009 & ,227 & 055 & ,027 &, $809^{* * *}$ & 455 & 191 & ,264 & ,218 & ,509 & 410 & 023 &, $618^{*}$ & ,000 & & & & & & \\
\hline $\mathrm{Li}$ & $\mathrm{r}$ & 582 & ,373 & 518 & 455 & 418 &, 518 & ,518 & 300 & 027 & 345 & 273 & , 127 & 482 &, $720^{*}$ & $733^{*}$ & ,400 & ,009 & ,000 & & & & & \\
\hline $\mathrm{Mn}$ & $\mathrm{r}$ & ,627 & 209 & ,209 & ,282 & 291 & 400 & 573 & ,509 & 164 & , 155 &, 118 & ,018 & ,509 & $861^{* *}$ &, $738^{* *}$ & 155 & 327 &, $864^{* *}$ & ,000 & & & & \\
\hline $\mathrm{Ni}$ & $\mathrm{r}$ & ,392 & ,210 & ,114 & ,410 & ,469 & $642^{*}$ & 383 & ,405 & 137, & ,351 &, 333 & ,638" & ,442 & 511 & ,002 & ,132 & ,369 & ,114 & 374 & ,000 & & & \\
\hline $\mathrm{Pb}$ & $\mathrm{r}$ & ,443 & 151 & ,082 &, $776^{* *}$ &, $740^{* *}$ & 475 & 105 & ,110 & ,493, &, $790^{* *}$ & ,068 & 155 & ,470 & 030 & ,126 & 096 & 041 & ,205 & 050 & 137 & ,000 & & \\
\hline $\mathrm{Si}$ & $\mathrm{r}$ & 600 & ,036 & ,127 & 127 & 318 & , 191 & 000 & 373 & ,091 & 055 & 109 &, 536 & 082 & ,383 & 219 & 382 & ,273 & 373 &, 364 & 082 & ,265 & ,000 & \\
\hline $\mathrm{Zn}$ & $\mathrm{r}$ & ,236 & ,227 & 018 & ,355 &, 318 & 582 & 355 & 018 & ,345 & ,145 &, 118 & 009 & ,245 & 442 & ,465 & 218 & 100 & ,336 & 445 & $670^{*}$ & 068 & ,209 & ,000 \\
\hline
\end{tabular}




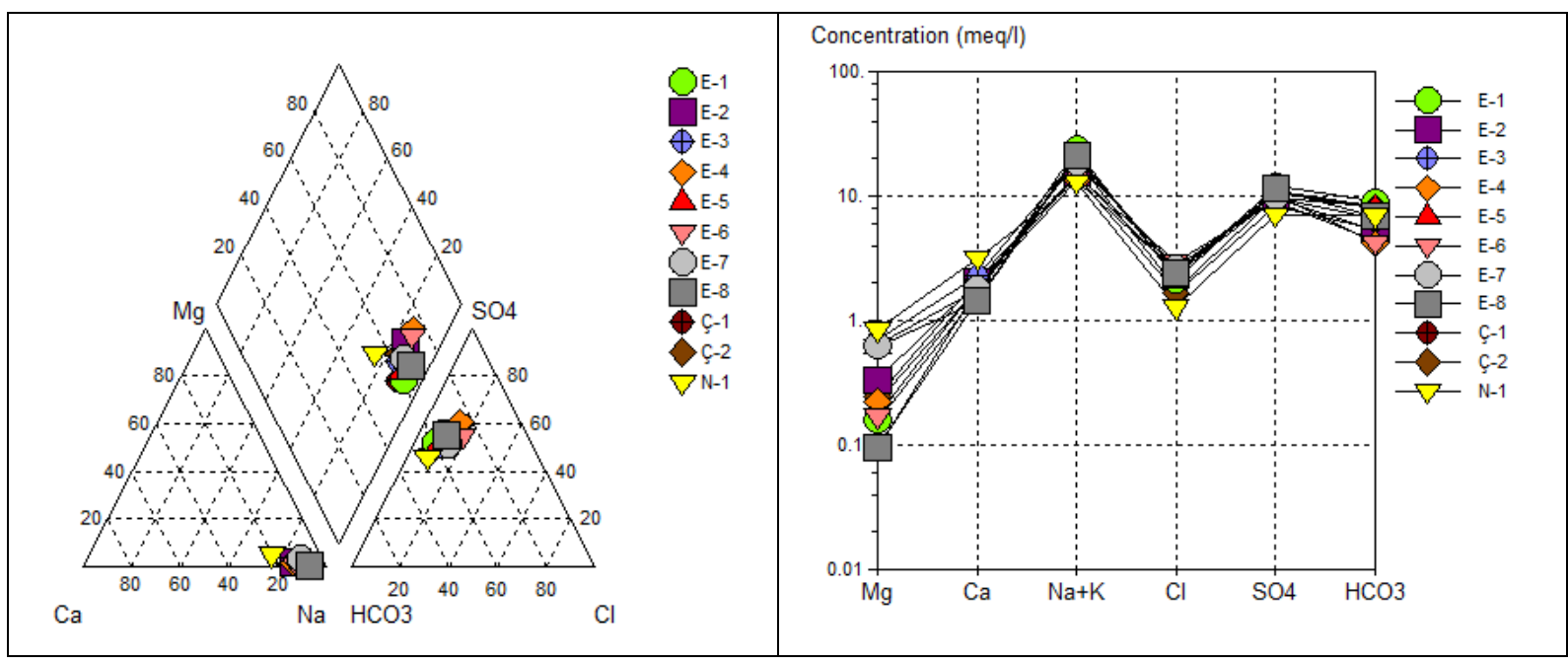

Şekil 3.2. Jeotermal akışkanın Piper ve Schoeller diyagramında gösterilmesi

Jeotermal akışkanın çevreye deşarj için uygun olup olmadığını belirlemek için sulama suyu kullanım sınıflamalarından olan Wilcox (1955) diyagramında kimyasal analiz sonuçları değerlendirilmiştir. Sodyum yüzdesi ve EC $(\mu \mathrm{S} / \mathrm{cm})$ değerleri karşılaştırılarak çizilen diyagramda sular "çok iyi-iyi", "iyi-kullanılabilir", "şüpheli-kullanılabilir", "şüpheli-kullanılmaz" ve "uygun değil" sınıflarına ayrılmaktadır. Sodyum yüzdesi; suyun toplam majör katyonları içinde $\% \mathrm{Na}$ değerini ifade eder. İyon derişimleri mek/l olmak üzere;

$$
\% N a=100 x \frac{N a}{(N a+K+C a+M g)}
$$

eşitliğiyle hesaplanmıştır. Elde edilen sonuçlara göre N-1 hariç tüm jeotermal akışkanın "şüpheli-kullanılmaz" sınıfında olduğu saptanmıştır (Şekil 3.3). Jeotermal akışkan, sahada herhangi bir reenjeksiyon kuyusu olmaması nedeni ile çevreye deşarj edilmektedir. Böylelikle akışkan yüzey ve yeraltı sularına karışarak bölgede yaşayan halkın geçim kaynağı olan tarım arazilerine ulaşmaktadır. Wilcox diyagramı sonuçlarına göre jeotermal akışkanın çevreye deşarjı önerilmemektedir.

Yüksek sıcaklık ve basınç altında jeotermal akışkan ile uzun süre etkileşim içerisinde olan kayaçtaki birçok metal(loid) çözünerek suya geçmektedir. Jeotermal sulardaki As konsantrasyonu 204.1-684.1 $\mu \mathrm{g} / 1$ aralığında değişmektedir. Ortalama As konsantrasyonu $430.41 \mathrm{mg} / \mathrm{l}$ olup, bu değer TS 266 (2005) tarafından tavsiye edilen maksimum değerden 43 kat daha fazladır. Jeotermal akışkandaki arseniğin ana kaynağı metamorfik kayaçlar olup, metamorfik kayaçlardaki As konsantrasyonu maksimum $660.4 \mathrm{mg} / \mathrm{kg}$ olarak tespit edilmiştir. (Gündüz ve ark., 2010). Ayrıca çevreye kontrolsüz olarak deşarj edilen jeotermal akışkan sebebiyle Gündüz ve ark. (2012) yüzeysel sularda sıcaklık artışı ile birlikte yüksek konsantrasyonda As bulunduğunu ifade etmiştir. Bor konsantrasyonu 2448-4203 $\mu \mathrm{g} / \mathrm{l}$ aralığında olup, ortalama değeri $3441.45 \mu \mathrm{g} / \mathrm{l}$ 'dir. En yüksek As ve B konsantrasyonu Eynal, en düşük konsantrasyon ise Naşa jeotermal alanında ölçülmüsşür. Su Kirliliği Kontrolü Yönetmeliği'ne (2008) göre Simav ovasında örnekleme yapılan tüm jeotermal akışkanlar As ve B için çok kirlenmiş sular (sınıf IV) sınıfında yer almaktadır. Naşa jeotermal akışkanı Mn konsantrasyonuna göre çok kirlenmiş sular (sınıf III), Çitgöl jeotermal akışkanı Fe konsantrasyonuna göre az kirlenmiş sular (sınıf II) sınıfında yer almaktadır. Bölgedeki jeotermal kaynaklardan faydalanmak için kurulmuş olan 7 adet yün yıkama tesisi jeotermal akışkanı kullandıktan sonra hiç bir arıtma yapmadan çevredeki derelere deşarj etmektedir (Gündüz ve ark., 2010). Bu durum bölgedeki kirlilik yükünü arttırmaktadır. Yaz aylarında ise konut 1sıtması amaçlı jeotermal kullanımı olmadığından jeotermal akışkan deşarjında belirgin bir azalma gözlenmektedir. 


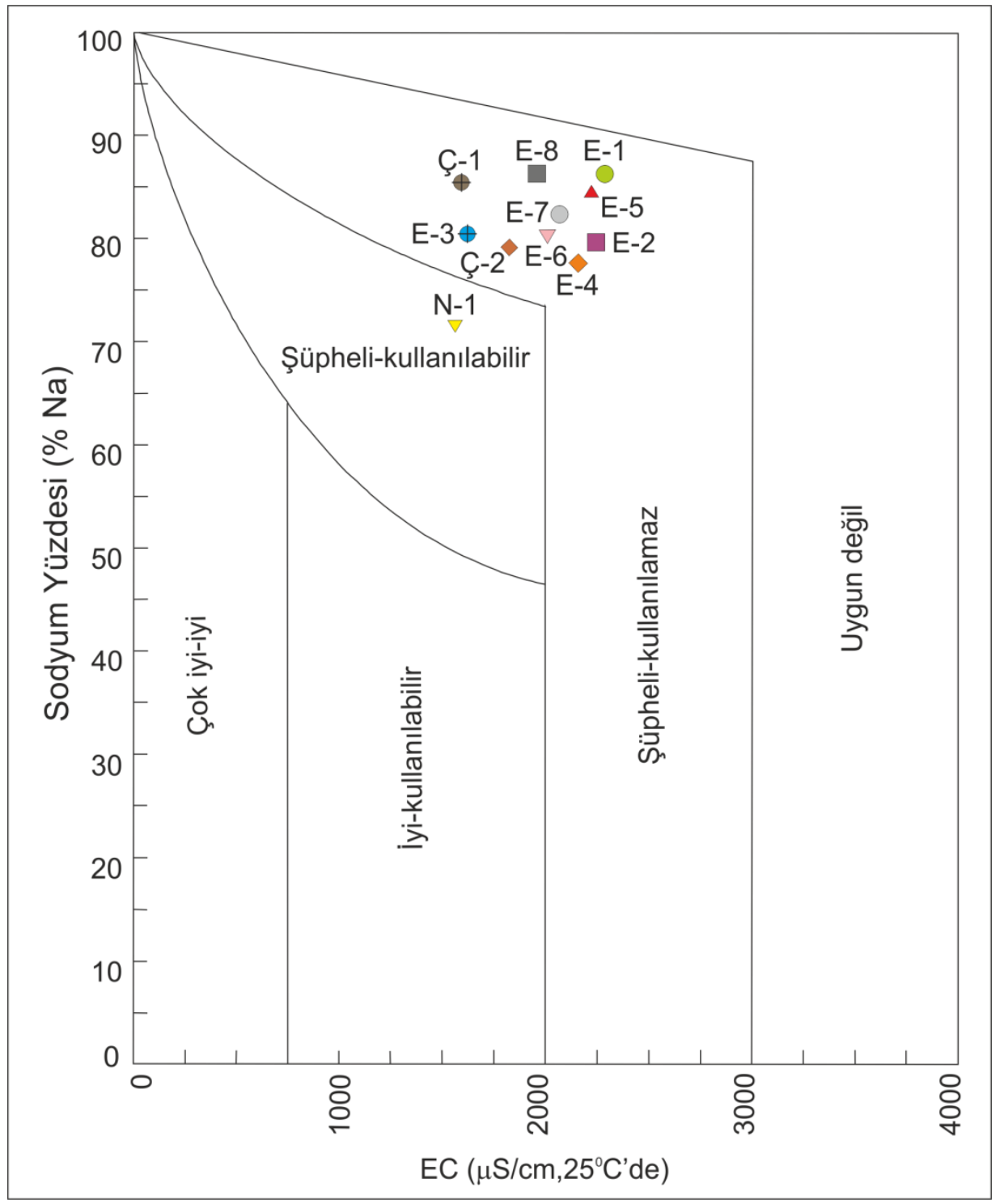

Şekil 3.3. Jeotermal akışkanın Wilcox diyagramında gösterilmesi

Jeotermal akışkanın hidrokimyasal analiz sonuçlarına uygulanan Pearson Korelasyon Analizi değerlendirmesi Çizelge 3.2'de sunulmuştur. Jeotermal akışkanın içerdiği $\mathrm{Na}^{+}$ve $\mathrm{K}^{+}$iyonları arasında pozitif yönlü çok kuvvetli bir korelasyon tespit edilmiştir $(\mathrm{r}=0,91, \mathrm{p}<0,01) . \mathrm{K}^{+} \mathrm{ve} \mathrm{Cl}^{-}$ 'ün sıcaklık ile arasında pozitif yönde kuvvetli bir korelasyon vardır $(\mathrm{r}=0.75, \mathrm{r}=0.83, \mathrm{p}<0.01)$. $\mathrm{K}^{+}$ve $\mathrm{Ca}^{2+}$ arasında negatif yönde kuvvetli bir korelasyon vardır $(\mathrm{r}=0.75, \mathrm{p}<0.01) . \mathrm{SO}_{4}{ }^{2-}$ ile $\mathrm{Na}^{+}$ve $\mathrm{K}^{+}$arasında pozitif yönde kuvvetli bir ilişki vardır $(\mathrm{r}=0.84, \mathrm{p}<0.01) . \mathrm{Ca}^{2+}$ ile $\mathrm{SO}_{4}{ }^{2-}$ arasında negatif yönde kuvvetli korelasyon vardır. Elementler içerisinde sadece Al ile EC arasında pozitif yönde kuvvetli bir ilişki tespit edilmiştir. Baryum ile sıcaklık arasında negatif yönde kuvvetli bir ilişki vardır. Demir ve $\mathrm{Cl}^{-}$arasında aynı zamanda $\mathrm{Li}^{+}$ve $\mathrm{Ba}$ arasında negatif yönde kuvvetli bir ilişki vardır. Mn ile $\mathrm{Ba}$ arasında pozitif, $\mathrm{Cr}$ ve $\mathrm{Li}$ arasında ise negatif yönlü kuvvetli bir ilişki vardır. Bununla birlikte $\mathrm{Pb}$ ile $\mathrm{Na}^{+}, \mathrm{K}^{+}$ve $\mathrm{SO}_{4}{ }^{2-}$ iyonları arasında negatif yönde kuvvetli bir ilişki tespit edilmiştir. Korelasyon sonuçlarına göre As ve B arasında anlamlı bir korelasyon tespit edilmemiştir. Arsenik ile Nikel arasında negatif yönde bir ilişki tespit edilmiştir $(\mathrm{r}=-0.63, \mathrm{p}<0.05)$. Nikel ile $\mathrm{Ca}^{2+}$ ve $\mathrm{Zn}$ arasında pozitif yönlü bir ilişki vardır. 
Bakır ile $\mathrm{Cr}$ ve $\mathrm{Fe}$ arasında negatif yönde, $\mathrm{Cl}^{-}$ile pozitif yönde ilişki vardır. Ayrıca $\mathrm{Cl}^{-}$ile $\mathrm{Ba}$ arasında negatif, $\mathrm{Cu}$ arasında ise pozitif yönde ilişki tespit edilmiştir.

Bu çalışma kapsamında, Eynal, Çitgöl ve Naşa jeotermal akışkanının kimyasal analiz sonuçlarına göre As, B, Fe ve Mn elementlerinin akışkanda yüksek konsantrasyonda olduğu tespit edilmiştir. Sıcak ya da soğuk su kaynaklarının özellikle As gibi yüksek toksik etkileri sahip metal(loid) içermesi ve bu suyun içerek tüketilmesi, tarım arazilerinin sulanması ya da çevreye bilinçsizce deşarjı halk sağlığının korunması açısından büyük önem taşımaktadır. Suda As varlığının arıtılmadığı ve özellikle içilerek tüketildiği durumlarda çok önemli sağlık sorunlarına sebep olmaktadır (Wang ve Mulligan, 2006). Yapılan çeşitli çalışmalar, arseniğin içme suyu ile alınması neticesinde insanlarda çeşitli deri lezyonları, deri ve akciğer kanseri başta olmak üzere kanserojenik etkiler gösterdiğini kanıtlamıştır (Sorg ve ark., 2014). Bu durum, yüksek As içeren jeotermal akışkanın çevresel etkileri açısından değerlendirilmesinin önemini daha da arttırmıştır.

\section{Sonuç}

Konut ve sera 1sıtılması gibi uygulamalar sonucunda ortaya çıkan atık jeotermal akışkan için en uygun bertaraf yöntemi yeraltına reenjeksiyondur. Reenjeksiyonun yapılmadiğ 1 durumlarda jeotermal akışkan aşırı çekim nedeni ile azalabilir hatta tükenme tehlikesi ile karşı karşıya gelebilir. Jeotermal akışkan ancak deşarj standartlarına uyulmak kaydıyla arıtılarak yüzeysel sulara deşarj edilmelidir. Çalışma sahasındaki tüm jeotermal alanlarda reenjeksiyon uygulaması bulunmamakta ve yeraltından çıkan jeotermal akışkanın tamamı kullanıldıktan sonra çevredeki derelere deşarj edilmektedir. Jeotermal akışkan kontrolsüz olarak deşarj edildiğinde çevresindeki su kaynaklarına karışarak ısıl ve kimyasal kirlenmeye (As, B, Fe, $\left.\mathrm{Mn}, \mathrm{Na}^{+}, \mathrm{SO}_{4}{ }^{2-}\right)$ neden olabilir. Gelecek çalışmalarda jeotermal alanların çevresindeki yüzey ve yeraltı sularının yanı sıra dere sedimanı ve toprağın jeotermal akışkandan ne kadar etkilendiğinin saptanması için mevsimsel örneklemeler yapılarak, analiz edilmesi önerilir.

\section{Teşekkür}

Bu çalışma Çanakkale Onsekiz Mart Üniversitesi Bilimsel Araştırma Koordinasyon Birimi tarafından FBA-2014-226 no'lu proje ile desteklenmiştir. Bu çalışma özgün araştırma makalesi niteliğindedir. 


\section{Kaynakça}

Akkuş İ., 2002. Jeotermal Uygulamalar ve MTA. Dokuz Eylül Üniversitesi, Jeotermal Enerji

Araştırma ve Uygulama Merkezi, Jeotermalde Yerbilimsel Uygulamalar Yaz Okulu Ders Notları, İzmir, Türkiye. 1-32.

Akkuş İ., Alan H., 2016. Türkiye'nin Jeotermal Kaynakları, Projeksiyonlar, Sorunlar ve Öneriler Raporu. TMMOB Jeoloji Mühendisleri Odası Yayınları, Ankara, Türkiye.

Ateş Ö., Tutkun S.Z., 2014. Simav (Kütahya) Depremlerinin Jeotermal Sistemlerdeki Hidrojeokimyasal Değişimleri. Türkiye Jeoloji Bülteni 57(3): 25-40.

Baba A., Armannsson H., 2006. Environmental Impact of the Utilization of Geothermal Areas. Energy Sources, Part B: Economics, Planning and Policy 1:267-278.

Baba A., Sözbilir H., 2012. Source of Arsenic Based on Geological And Hydrogeochemical Properties of Geothermal Systems in Western Turkey. Chemical Geology 334(12): 364377.

Bayram A.F., Şimşek Ş., 2005. Hydrogeochemical and Isotopic Survey of Kütahya-Simav Geothermal Field. World Geothermal Congress Proceedings, 1-11.

Baysal R.T., Gündüz O., 2016. The Impacts of Geothermal Fluid Discharge on Surface Water Quality with Emphasis on Arsenic. Water, Air, and Soil Pollution 227:165.

Davraz A., Aksever F., Afşin M., 2017. Assessment of Stream Water Chemistry and Impact of Geothermal Fluid in the up-Buyuk Menderes Basin, Turkey. Environmental Science and Pollution Research 24: 26806-26820.

Eroğlu A., Aksoy N., 2003. Jeotermal Suların Kimyasal Analizi, VI. Ulusal Tesisat Kongresi, Jeotermal Enerji Semineri Kitapçı̆̆ı. 149-183.

Gemici Ü., Tarcan G., 2002. Hydrogeochemistry of the Simav Geothermal Field, Western Anatolia. Journal of Volcanology and Geothermal Research 116: 215-233. 
Gündüz O., Şimşek C., Hasözbek A., 2010. Arsenic Pollution in the Groundwater of Simav Plain, Turkey: Its Impact on Water Quality and Human Health. Water, Air and Soil Pollution 205(1): 43-62.

Gündüz O., Mutlu M., Elçi A., Şimşek C., Baba A., 2012. Jeotermal Akışkan Deşarjının Yüzeysel Su Kalitesine Etkisi: Örnek Saha Simav Ovası Kütahya. Çevre Bilim \& Teknoloji 3(4): 231-246.

Mertoğlu O., Şimşek Ş., Başarır N., 2015. Geothermal Country Update Report of Turkey (2010-2015). World Geothermal Congress Proceedings, Melbourne, Australia.

MTA, 2001. Türkiye Jeotermal Envanteri. MTA Yayınları, Ankara.

Nicholson K., 1993. Geothermal Fluids: Chemistry and Exploration Techniques. Springer, Berlin.

Özen Balaban T., Bülbül A., Tarcan G., 2017. Review of water and soil contamination in and around Salihli geothermal field (Manisa, Turkey). Arabian Journal of Geosciences 10: 523.

Palabıyık Y., 2006. Kütahya-Simav Jeotermal Sahasının Jeokimyasal Değerlendirmesi. Yüksek Lisans Tezi. İstanbul Teknik Üniversitesi, Fen Bilimleri Enstitüsü, İstanbul, Türkiye.

Piper A.M., 1944. A Graphic Procedure in the Geochemical Interpretation of Water Analyses. Transactions of American geophysical Unions 25: 914-923.

Schoeller H., 1955. Geochimie des Eaux Souterraines, Rev. Inst. Franc. Petrole, Paris. 219246.

Sorg T.J., Chen A.S.C., Wanga L., 2014. Arsenic Species in Drinking Water Wells in the USA with High Arsenic Concentrations. Water Research 48: 156-169.

Su Kirliliği Kontrolü Yönetmeliği, 2008. Online. 10.03.2019, http://www.mevzuat. gov.tr/Metin.Aspx?MevzuatKod=7.5.7221\&sourceXmlSearch=\&MevzuatIliski=0 Şahinci A., 1991. Doğal Suların Jeokimyası. Reform Matbaası. İzmir, Türkiye. 
Şanlıyüksel D., Baba A., 2011. Hydrogeochemical and Isotopic Composition of a Low Temperature Geothermal Source in Northwest Turkey: Case Study of Kirkgecit Geothermal Area. Environmental Earth Sciences 62: 529-540.

Şanlıyüksel Yücel D., Yücel M.A., 2017. Terk Edilmiş Kömür Ocaklarında Oluşan Maden Göllerinin Hidrokimyasal Özelliklerinin Belirlenmesi ve İnsansız Hava Aracı ile Üç Boyutlu Modellenmesi. Pamukkale Üniversitesi Mühendislik Bilimleri Dergisi 23(6): 780-791.

Şimşek C., Gündüz O., 2007. IWQ Index: a GIS-integrated Technique to Assess Irrigation Water Quality. Environmental Monitoring and Assessment 128(1-3): 277-300.

TS 266, 2005. Sular - İnsanî Tüketim Amaçlı Sular. Türk Standardı.

Şimşek Ş., 2015. Dünya'da ve Türkiye'de Jeotermal Gelişmeler. III. Jeotermal Kaynaklar Sempozyumu Bildiriler Kitab1. 1-17.

Wang, S., Mulligan, C.N., 2006. Occurrence of Arsenic Contamination in Canada: Sources, Behavior and Distribution. Science of the Total Environment, 366:2-3, 701-721.

Wilcox L.V., 1955. Classification and Use of Irrigation Waters, U.S. Dept. Agric. Circ. 969, Washington D.C., 19 p.

Zaim A., Çavşi H., 2018. Türkiye'deki Jeotermal Enerji Santrallerinin Durumu. Mühendis ve Makine 59(691): 45-58. 